Int. J. Environ. Sci. Tech.

(C) Spring 2006, Vol. 3, No. 2, pp. 103-112

\title{
Effect of trace metals on halophilic and mixed cultures in anaerobic treatment
}

\author{
${ }^{1}$ K. Krongthamchat, ${ }^{2 *}$ R. Riffat and ${ }^{3}$ S. Dararat \\ ${ }^{1}$ Environmental Health Science Department, Khon Kaen University, Khon Kaen, Thailand \\ ${ }^{2}$ Civil and Environmental Engineering Department, George Washington University, Washington, DC, USA \\ ${ }^{3}$ Environmental, Ecological and Energy Department, Thailand Institute of Scientific and Technological Research, \\ Bangkok, Thailand
}

Received 20 January 2006;

revised 6 March 2006;

accepted 15 March 2006;

available online 20 April 2006

\begin{abstract}
Trace metals are known to stimulate the activity of anaerobic methanogenic bacteria involved in the degradation of organic matter. The objective of this research was to investigate the effect of three trace metals, iron, nickel and cobalt on the activity of halophilic methanogens, digester sludge and a mixed culture of halophilic bacteria and digester sludge, at various salt concentrations. Iron slightly stimulated both initial and maximum specific methanogenic activity (SMA) of halophilic methanogens at all salt concentrations. Iron addition was also able to increase both initial and maximum SMA of the mixed culture. Iron could not stimulate either initial or maximum SMA of digester sludge at salt concentrations of more than $10 \mathrm{~g} / \mathrm{L}$. Adding cobalt showed no benefit on the initial and maximum SMA of halophilic methanogens. A slight increase in the initial SMA was observed in mixed culture when cobalt was injected to the system containing sodium concentrations of $10-30 \mathrm{~g} / \mathrm{L}$. At salt concentrations above $40 \mathrm{~g} / \mathrm{L}$, cobalt could stimulate the maximum SMA of mixed culture. No benefits were found when cobalt was added to the digester sludge at sodium concentrations higher than $20 \mathrm{~g} / \mathrm{L}$. Nickel was observed to increase the initial SMA of digester sludge at all salt concentrations, and the maximum SMA of mixed culture at salt concentrations of 30-50 g/L.
\end{abstract}

Key words: Halophilic methanogens, iron, nickel, cobalt, digester sludge, anaerobic

*Corresponding Author, E-mail: riffat@gwu.edu

\section{INTRODUCTION}

Microorganisms need all the essential ingredients for their growth including trace metals. Trace metals are generally known to stimulate the rate of organic degradation in methanogenesis processes (Speece, 1996). Iron (Fe), nickel (Ni) and cobalt (Co) are the most significant trace metals to stimulate the bioactivity of microorganisms (Takashima and Speece, 1989). Researchers have determined that the addition of adequate concentrations of these nutrients can enhance the activity of methanogenesis processes (Speece et al., 1983; Mah et al., 1978). Trace metals are necessary for all microorganisms. An adequate amount of bioavailable form is an essential requirement for the growth of microorganisms. The fact that trace metals are present in a treatment process does not assure their bioavailability. Even industrial wastewater has a significant concentration of trace elements. Measurement by atomic absorption analysis does not indicate the presence of bioavailable trace metals, because they may be too strongly chelated (Speece, 1996). Wastewater containing high concentrations of salt is generally difficult to treat using standard anaerobic treatment processes. High sodium concentrations can be toxic to the bacteria. This adverse effect can be overcome by using bacterial cultures from saline environments. In addition to anaerobic archaebacteria, halophilic methanogens have been found in hypersaline environments (Zhilina, 1986). Halophilic methanogens isolated from mangrove soil was observed to have high potential for anaerobic degradation of organic pollutants in wastewater containing various salt concentrations (Krongthamchat and Riffat, 2001). A study was conducted by Riffat and Krongthamchat (2005) to determine the specific methanogenic activities (SMA) of halophilic cultures and compare them with the activities of digester sludge bacteria, and a mixed culture of halophiles and digester sludge. High sodium chloride concentrations had an 
K. Krongthamchat, et al.

adverse effect on digester sludge bacteria. But the mixed culture performance was similar to that of the halophilic culture in long term studies. The objective of this research was to investigate the influence of trace metals on three types of bacterial cultures in high salinity. The three cultures selected were halophilic methanogens, digester sludge and a mixed culture of halophiles and digester sludge. Three inorganic trace metals, iron, nickel and cobalt, were used in this research. The effects of the trace metals were quantified in terms of two parameters, (i) lag period, and (ii) specific methanogenic activity, as described by Hovious (1973) and Hulshoff-Pol et al., (1986). Results of these experiments will provide some information as to whether trace metals reduce or increase the toxicity of sodium, and/or stimulate microorganisms in the process. This research was performed in the Environmental Engineering Laboratory at George Washington University in Washington, DC, USA, between 1999 and 2001.

\section{MATERIALS AND METHODS}

Bacterial cultures

Two types of bacterial cultures were used in this research, halophilic culture and digester sludge. The halophilic culture was obtained from anaerobic mangrove soil from Thailand, and cultivated in a continuously stirred tank reactor (CSTR) for 6 months at $35^{\circ} \mathrm{C}$, at a constant $\mathrm{pH}$ of $7.0 \pm 0.2$ and acetate utilization rate (AUR) of $1 \mathrm{~g} / \mathrm{Ld} .15 \mathrm{~g} / \mathrm{L}$ of $\mathrm{NaCl}$ was fed to the reactor each day. In order to reduce the population of sulfate-reducing bacteria in the mangrove soil, $20 \mathrm{mM}$ of molybdate was added to the reactor in a one-time slug dose. Anaerobic digester sludge was obtained from a wastewater treatment plant in Washington, DC. The stock culture of this biomass was cultivated in a $2 \mathrm{~L}$ vessel, operated at a 50 d SRT (Solids Retention Time) and a temperature of $35^{\circ} \mathrm{C}$. The mixed culture was obtained by mixing the halophilic culture and anaerobic digester biomass in the ratio of 1:2.

\section{Substrate}

Acetate was added as the sole substrate. A nutrient solution/basal media was prepared with the following components, and added to the substrate: $0.5 \mathrm{mg} / \mathrm{L}$ $\mathrm{AlCl}_{3} .6 \mathrm{H}_{2} \mathrm{O} ; 0.5 \mathrm{mg} / \mathrm{L} \mathrm{H}_{3} \mathrm{BO}_{3} ; 10 \mathrm{mg} / \mathrm{L} \mathrm{KI} ; 0.5 \mathrm{mg} / \mathrm{L}$ $\mathrm{CuCl}_{2} .2 \mathrm{H}_{2} \mathrm{O} ; 10 \mathrm{mg} / \mathrm{L} \mathrm{MnCl}_{2} .2 \mathrm{H}_{2} \mathrm{O} ; 0.5 \mathrm{mg} / \mathrm{L}$ $\mathrm{Na}_{2} \mathrm{MoO}_{4} .2 \mathrm{H}_{2} \mathrm{O} ; 0.5 \mathrm{mg} / \mathrm{L} \mathrm{Na}_{2} \mathrm{SeO}_{4} ; 0.5 \mathrm{mg} / \mathrm{L} \mathrm{NH}_{4} \mathrm{VO}_{3}$; $0.5 \mathrm{mg} / \mathrm{L} \mathrm{NaWO} \cdot 2 \mathrm{H}_{2} \mathrm{O} ; 40 \mathrm{mg} / \mathrm{L} \mathrm{FeCl}_{2} .6 \mathrm{H}_{2} \mathrm{O} ; 10 \mathrm{mg} / \mathrm{L}$ $\mathrm{CoCl}_{2} .6 \mathrm{H}_{2} \mathrm{O} ; 0.5 \mathrm{mg} / \mathrm{L} \mathrm{NiCl}_{2} .6 \mathrm{H}_{2} \mathrm{O} ; 0.5 \mathrm{mg} / \mathrm{L} \mathrm{ZnCl}_{2} ; 1200$ $\mathrm{mg} / \mathrm{L} \mathrm{NH}_{4} \mathrm{Cl} ; 80 \mathrm{mg} / \mathrm{L}\left(\mathrm{NH}_{4}\right)_{2} \mathrm{HPO}_{4} ; 10 \mathrm{mg} / \mathrm{L} \mathrm{NaPO}_{3} ; 300$ $\mathrm{mg} / \mathrm{L} \mathrm{Na}_{2} \mathrm{~S} .9 \mathrm{H}_{2} \mathrm{O} ; 400 \mathrm{mg} / \mathrm{L} \mathrm{KCl} ; 405 \mathrm{mg} / \mathrm{L} \mathrm{CaCl}_{2} .2 \mathrm{H}_{2} \mathrm{O}$;
10 mg/L Cystein; and 6000 mg/L NaHCO ${ }_{3}$.

\section{Experimental procedure}

The experiments were conducted in $125 \mathrm{~mL}$ glass serum bottles sealed with a rubber septum. The serum bottles were incubated until the background acetate was utilized and the corresponding gas was vented. The acetate concentration (7000 mg/L) and sodium chloride in basal medium stock solution were added to each bottle. This level of acetate is sufficient to allow the acetateconverting methanogens to operate at their maximum rate (Speece, 1996). Sodium chloride concentrations of $0,10,20,30,40$, and $50 \mathrm{~g} / \mathrm{L}$ were used. Each serum bottle contained $50 \mathrm{~mL}$ of a basal medium including sodium chloride, substrate and $500 \mathrm{mg} / \mathrm{L}$ biomass. Three trace metal compounds, ferrous chloride $\left(\mathrm{FeCl}_{2}\right)$, cobalt chloride $\left(\mathrm{CoCl}_{2}\right)$ and nickel chloride $\left(\mathrm{NiCl}_{2}\right)$ were selected for addition at concentrations of $1,0.1$ and $0.1 \mathrm{mg} / \mathrm{L}$, respectively. These concentrations were selected based on previous studies by researchers (Speece, 1996). Each trace metal was added separately to a serum bottle. One set of control experiments were conducted without any trace metals. The experiments were performed at a temperature of $35 \pm 1^{\circ} \mathrm{C}$. Gas production was measured daily and was thus a measure of methanogenic activity. Any variation greater than $10 \%$ was considered to impact the bacteria in a stimulatory/inhibitory way.

\section{Parameter calculation}

Two parameters were calculated from the experimental data:

(i) Lag phase. Lag phase is defined as the time required by bacteria to acclimate to their new environment (Metcalf and Eddy, 2003). In a batch experiment, daily gas production was recorded, and the lag period was the phase prior to exponential gas generation. The purpose of this study was to investigate the length of time required by the bacteria to adapt to the new high stress environment.

(ii) specific methanogenic activity (SMA):

SMA refers to the rate at which methanogens degrade substrate to produce methane and carbon dioxide. SMA was calculated from the slope of the methane production curve, and expressed in units of g acetate/g VSSd. The SMA can evaluate the behavior of the culture in a toxic environment. This study focused on the initial and maximum SMA. Both initial and maximum SMA were determined from a linear methane production accumulation slope over the first three days and maximum slope $\left(r^{2}>0.95\right)$, respectively, and divided by the total biomass. 


\section{RESULTS}

\section{Effect of iron}

The daily gas production pattern of halophilic methanogens supplemented with $1 \mathrm{mg} / \mathrm{L}$ of Ferrous chloride $\left(\mathrm{FeCl}_{2}\right)$, at various concentrations of sodium chloride is illustrated in Fig. 1. Halophilic methanogens required time to acclimate to the environment before starting bacterial activity. The lag periods for various sodium chloride concentrations were in the range of 14 days. The lag periods and time to reach peak gas production for all three cultures, halophilic, mixed culture and digester sludge, were evaluated with and without iron. Adding iron, as a trace element, had the capacity to reduce the lag time of mixed culture. However, in case of digester sludge, the lag periods were extended and delayed the time to reach the maximum gas production. No significant difference in lag period was observed for halophilic bacteria with or without additional iron. Fig. 2 (4.55) illustrates the initial activity of halophilic bacteria with and without iron. Iron had the potential to increase initial SMA when sodium chloride was increased from 0 to $20 \mathrm{~g} / \mathrm{L}$, and then initial SMA was gradually decreased when sodium content was higher than $20 \mathrm{~g} / \mathrm{L}$. It appeared that iron may reduce bacterial stress, since the initial SMA with iron addition was higher than that without iron. When maximum SMA values were compared, the SMA with iron was higher than that without iron in the medium, for every concentration of sodium chloride. In general, one of the significant halophilic enzymes is cytochrome oxidase (Baxter and Gibbons, 1956). Adding iron in the medium is regarded as adding stimulant to the cytochrome system, to produce the enzyme required to maintain a constant internal osmotic pressure. Therefore, bacteria are able to keep their osmotic balance under high sodium stress. MacLeod and Onofrey (1957) reported that supplements of 0.005-0.01 ppm of iron in a sea water medium increased the rate and extent of growth of a marine bacterium. In the current research, additional iron in the medium caused the increase of SMA of halophilic bacteria, which supports the results of the research done by MacLeod and Onofrey. Fig. 3 (4.57) illustrates the comparison of initial SMA values for digester sludge, with and without iron addition. The initial SMA only appeared in the salt concentration of $0-10 \mathrm{~g} / \mathrm{L}$. Ferrous chloride was unable to stimulate digester sludge bacteria when the medium contained more than $10 \mathrm{~g} / \mathrm{L}$ sodium chloride, and no initial SMA could be observed. Similar trend was observed for maximum SMA values. The initial SMA for mixed culture with and without supplemental iron is presented in Fig. 4 (4.59). It was observed that iron had the potential to increase the initial SMA of mixed culture at all sodium concentrations. With iron addition, the initial SMA of mixed culture was higher than the initial SMA of the culture without iron addition. The highest maximum SMA with supplemental iron occurred at a salt concentration of 10 g/L as shown in Fig. 5 (4.60). The higher salt also had an effect on the maximum SMA. Fig. 5 indicates that iron had the capacity to stimulate the mixed culture to achieve a higher value of maximum SMA at a shorter time, as compared to that without supplemental iron in the medium.

\section{Effect of cobalt}

The addition of $0.1 \mathrm{mg} / \mathrm{L}$ of cobalt chloride $\left(\mathrm{Co} \mathrm{Cl}_{2}\right)$ was able to slightly reduce the lag period of halophilic and mixed cultures. The reduction of lag period of digester sludge was observed at all sodium contents. Addition of cobalt also reduced the time to reach peak gas production of digester sludge and mixed culture at sodium concentration of $50 \mathrm{~g} / \mathrm{L}$. The specific methanogenic activity of the halophilic culture, resulting from addition of $0.1 \mathrm{mg} / \mathrm{L}$ cobalt chloride is shown in Fig. 6 (4.61). With supplemental cobalt, the initial SMA increased with increasing sodium concentration between 0-20 g/L and declined when sodium content was raised above $20 \mathrm{~g} / \mathrm{L}$. At high sodium concentration of $40 \mathrm{~g} / \mathrm{L}$, the initial SMA of culture with additional cobalt declined to one-fourth of the value for bacteria without supplemental cobalt. Similar trend was observed with maximum SMA values. The purpose of adding cobalt was to promote the bacterial activity, however, the result was contradictory. It did not increase the maximum SMA, and more time was required to achieve the maximum SMA value. This may indicate that cobalt chloride was unable to stimulate the growth of halophilic bacteria. The addition of cobalt chloride was not able to impact or improve the initial SMA of digester sludge. The maximum SMA was increased with cobalt addition (Fig. 7) (4.64) at salt concentrations between $0-20 \mathrm{~g} / \mathrm{L}$, and required almost the same time to reach the maximum SMA as the culture without supplemental cobalt. Cobalt was unable to promote bacterial activity when the sodium chloride was increased more than $20 \mathrm{~g} / \mathrm{L}$. However, it reduced the time to achieve the maximum SMA. 


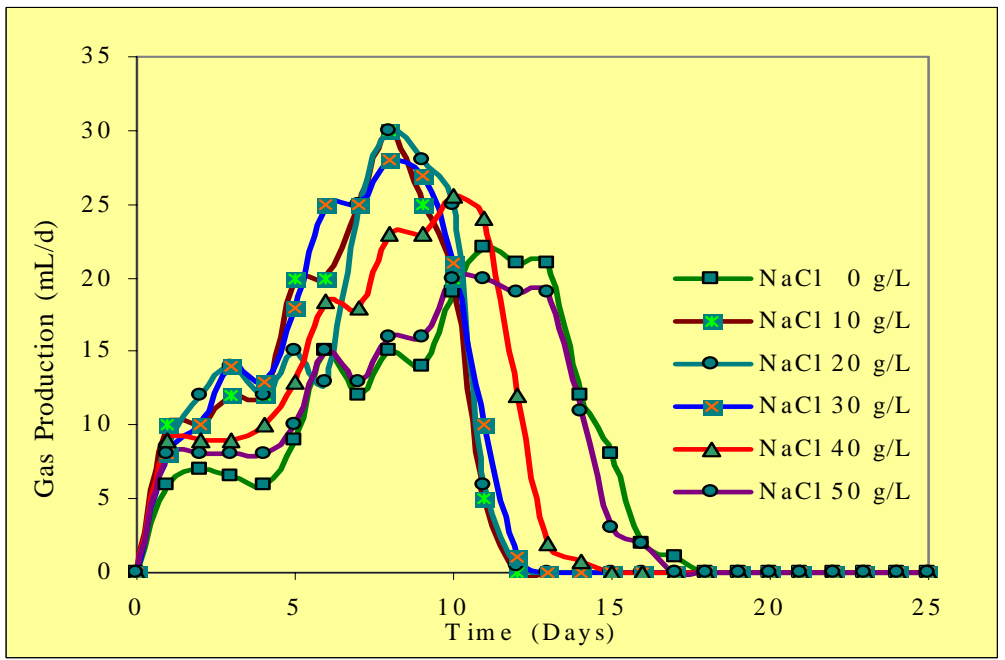

Fig. 1: Daily gas production of halophilic methanogens at various salt concentrations with supplemental iron

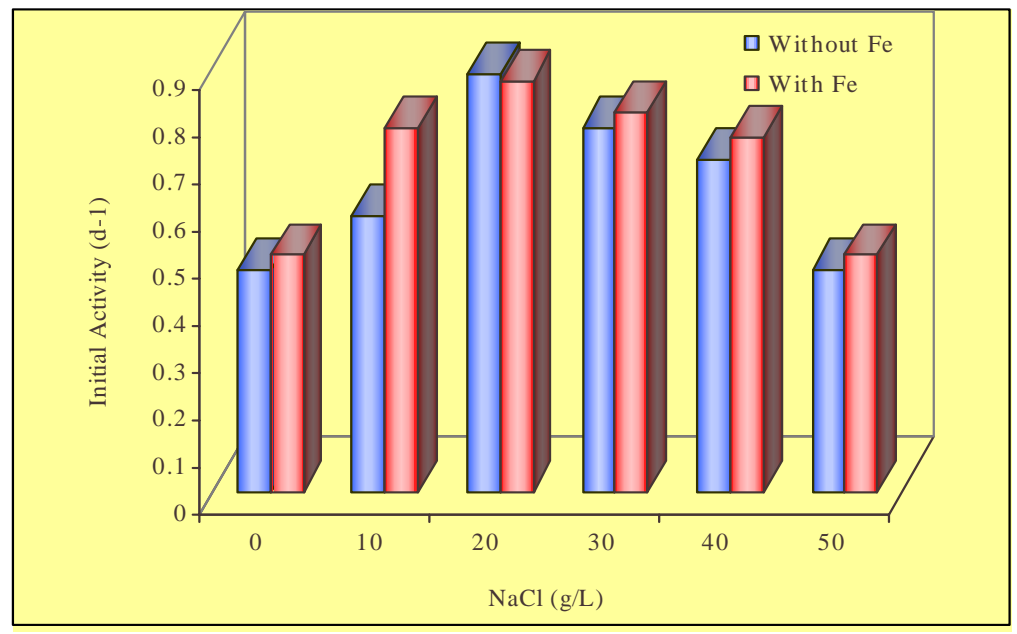

Fig. 2: Initial SMA of halophilic methanogens with and without iron

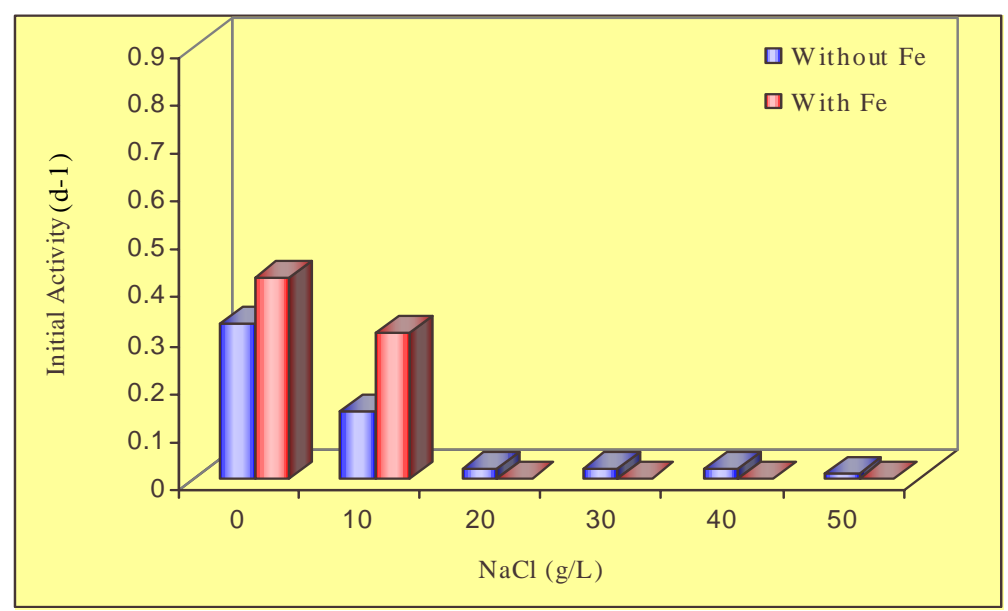

Fig. 3: Initial SMA of digester sludge with and without iron addition 
Effect of trace...

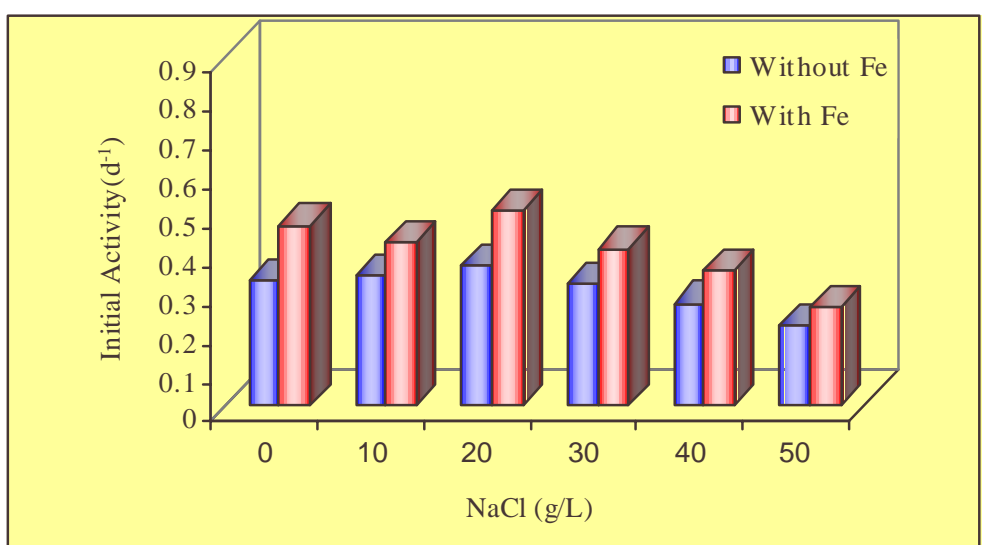

Fig. 4: Initial SMA of mixed culture with and without iron addition

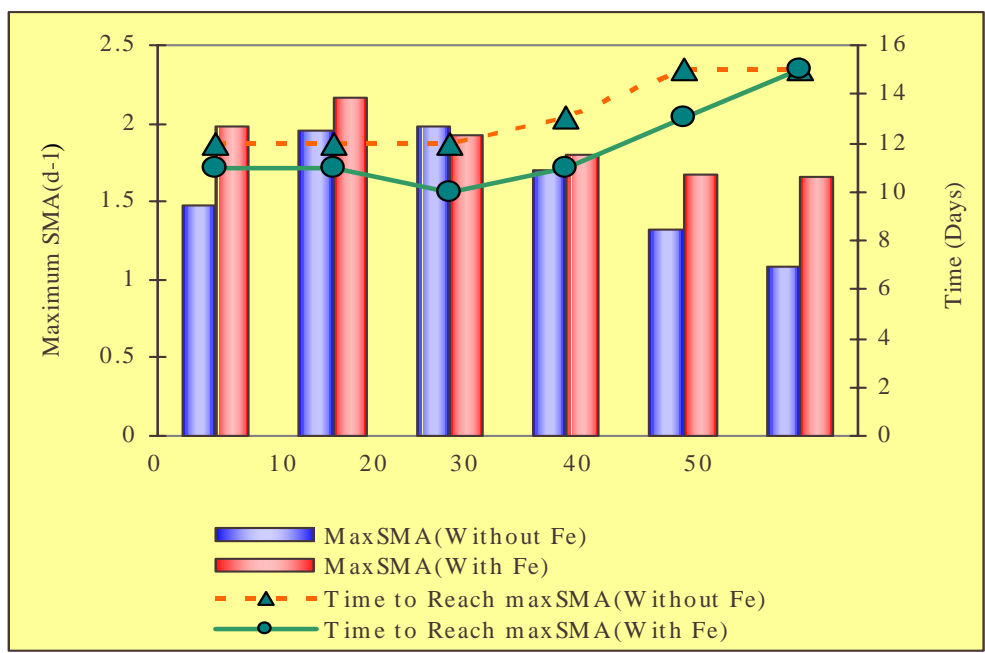

Fig. 5: Maximum SMA of mixed culture with and without iron addition

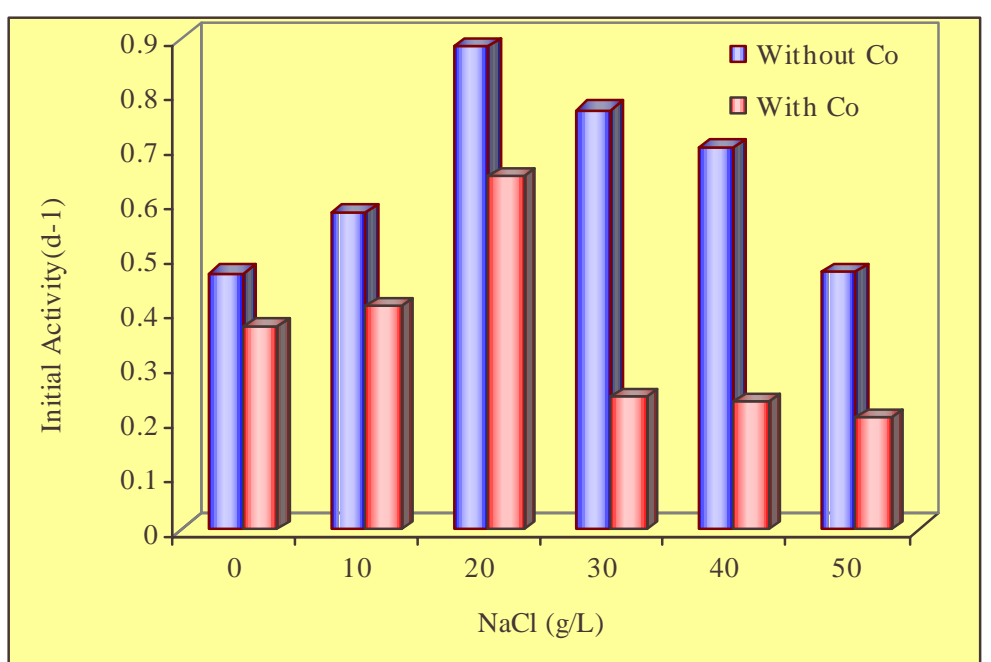

Fig. 6: Initial SMA of halophilic methanogens with and without cobalt addition 
For example, with cobalt in the salt medium of $50 \mathrm{~g} / \mathrm{L}$, the culture required 25 days to achieve maximum activity, while it needed 34 days for the culture without cobalt. The initial SMA of mixed culture with and without adding cobalt is illustrated in Fig. 8 (4.65). It was observed that cobalt chloride could stimulate initial SMA when the sodium chloride concentration was between 10-30 g/L. At lower and higher salt concentrations, the initial SMA was lower than the SMA for culture without cobalt. In the long term effect, the result indicated that with cobalt addition, the activity of culture in the high salt concentration was improved, and required less time than the culture without additional cobalt (Fig. 9) (4.66). At salt concentrations of 40 and $50 \mathrm{~g} / \mathrm{L}$, the maximum SMA of the culture with additional cobalt was $40 \%$ and $70 \%$ higher, respectively, than the culture without added cobalt. With lower salt content, the culture with cobalt required less time to achieve the maximum SMA.

\section{Effect of nickel}

With the addition of $0.1 \mathrm{mg} / \mathrm{L}$ of nickel chloride $\left(\mathrm{NiCl}_{2}\right)$ as a trace metal, no lag period was observed for halophilic bacteria at sodium concentrations between $20-50 \mathrm{~g} / \mathrm{L}$. It was found that, using nickel as a trace metal could stimulate the activity of all three types of cultures, decrease the lag period and accelerate the time required to reach peak gas production, especially in digester sludge bacteria under salt stress. For halophilic culture, the addition of nickel as a trace metal did not have any effect on the initial or maximum SMA. No significant difference was observed between the activity of the halophilic cultures with and without nickel addition. The initial SMA of digester sludge with and without additional nickel is shown in Fig. 10 (4.69). Addition of nickel could activate the culture so that the initial SMA was higher than that without supplemental nickel at all sodium chloride concentrations. Nickel could assist the culture to improve their maximum SMA at low salt concentrations (Fig. 11) (4.70). From 20-40 g/L NaCl, the activity of bacteria with added nickel was lower than that without nickel. Nickel could only reduce the time required to achieve themaximum SMA. The initial SMA of mixed culture with and without supplemental nickel is illustrated in Fig. 12 (4.71). From this Fig., it can be seen that the initial SMA value of the culture with additional nickel was similar for all sodium contents, and had a higher value than the culture without added nickel, especially at the high salt concentration of $40-50 \mathrm{~g} / \mathrm{L}$. The maximum SMA of mixed culture with added nickel was also higher than that without additional nickel (Fig. 12) (4.72). At high sodium chloride concentration, nickel seemed to have greater ability to stimulate the culture than at lower salt concentration. However, nickel could not assist the culture to reduce the time required to reach the maximum SMA.

\section{DISCUSSION AND CONCLUSIONS}

The generally accepted view is that trace metals are necessary for the microorganisms. Previous researchers have reported that iron, cobalt and nickel were able to stimulate methanogenesis (Speece, 1996). Hence, this research investigated the effects of three trace metals including iron, cobalt and nickel on halophilic, digester sludge and mixed culture in terms of specific methanogenic activity. The results were compared with the activity of bacteria without supplemental trace metals.

The following are the conclusions from this research: 1. For halophilic bacteria with supplemental iron in the medium, the trend of initial SMA was higher than the trend without iron at all sodium concentrations. The initial SMA, was increased in the sodium range of $0-20 \mathrm{~g} / \mathrm{L}$. Above sodium content of $20 \mathrm{~g} / \mathrm{L}$, it was similar to the initial SMA without iron. Nickel was able to increase the initial SMA of halophilic culture in the sodium range of 0 $-20 \mathrm{~g} / \mathrm{L}$, but the value of initial SMA was less than that with supplemental iron. At sodium chloride concentration between 40-50 g/L, nickel showed inhibition effects on the halophilic bacteria. The initial SMA value was less than the value of the culture without additional trace metals. Poor result was obtained with cobalt addition to the halophilic bacteria. Cobalt reduced the initial activity of halophilic bacteria, especially at the higher salt concentrations. Similar trends were observed with maximum SMA values.

2. For digester sludge, the initial SMA of the culture was nearly zero at high salt concentrations. Supplemental iron in the medium was able to reduce sodium toxicity. The initial SMA of digester sludge was higher than that without iron supplement, in the salt concentration up to $20 \mathrm{~g} / \mathrm{L}$. However, the initial SMA rapidly dropped to zero when the salt concentration was increased above $30 \mathrm{~g} / \mathrm{L}$. Nickel chloride seemed to reduce sodium toxicity in the short term. The initial SMA of culture with supplemental nickel was higher than that without nickel at all sodium concentrations. Adding cobalt to the digester sludge seemed to have an adverse effect in the short term. The initial SMA was less than that without cobalt, and showed a value of zero when the salt was increased to more than $20 \mathrm{~g} / \mathrm{L}$. 
Effect of trace...

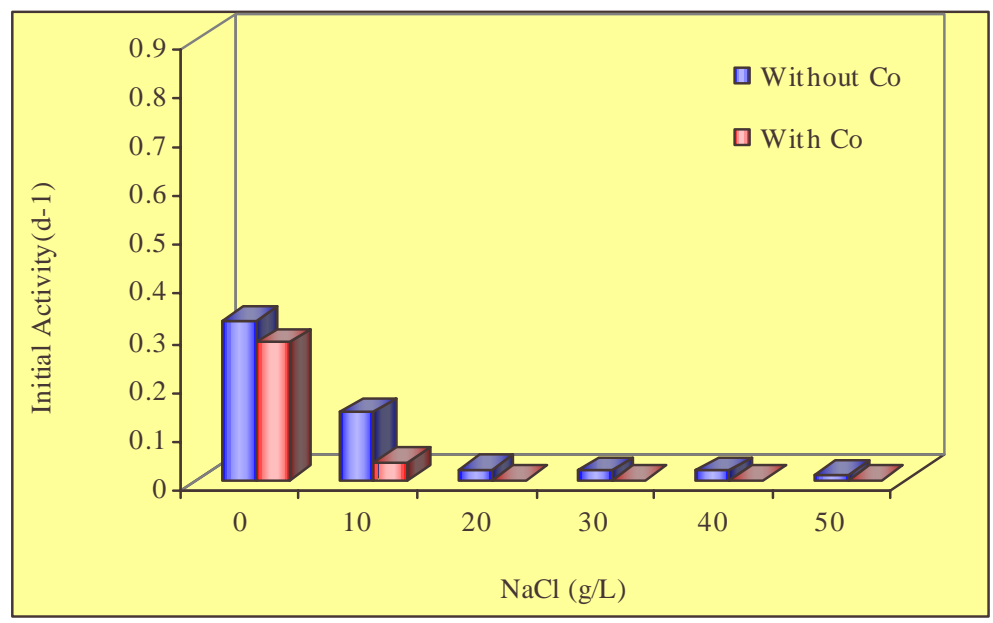

Fig. 7: Initial SMA of digester sludge with and without cobalt addition

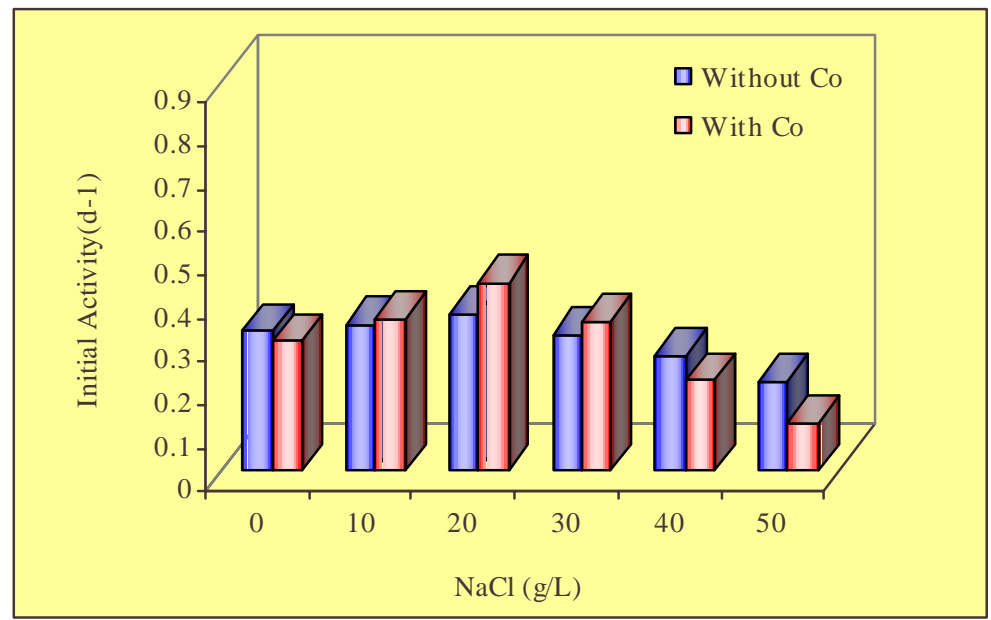

Fig. 8: Initial SMA of mixed culture with and without cobalt addition

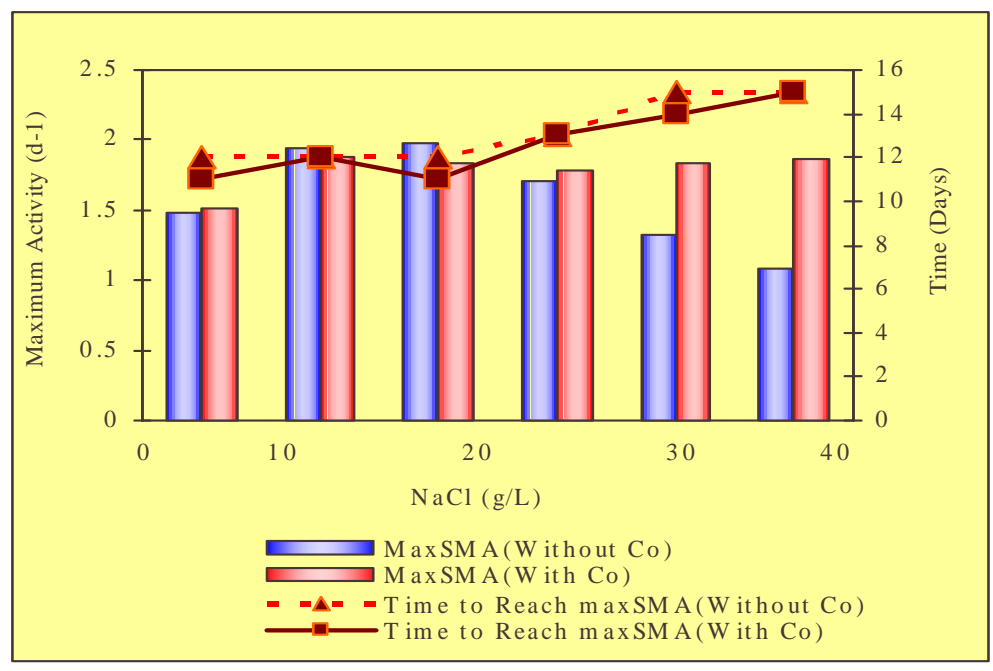

Fig. 9: Maximum SMA of mixed culture with and without cobalt addition 


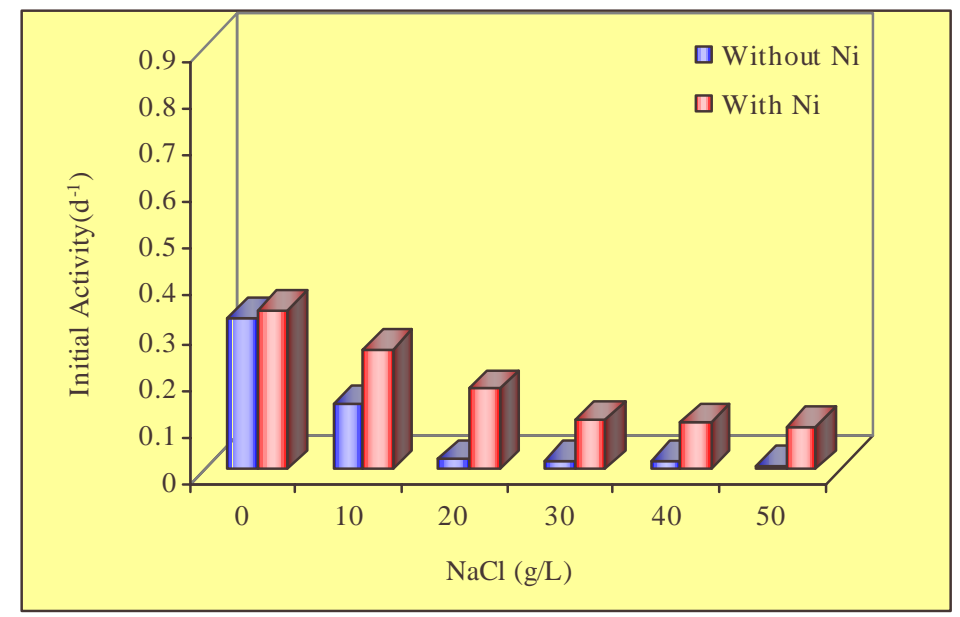

Fig. 10: Initial SMA of digester sludge with and without nickel addition

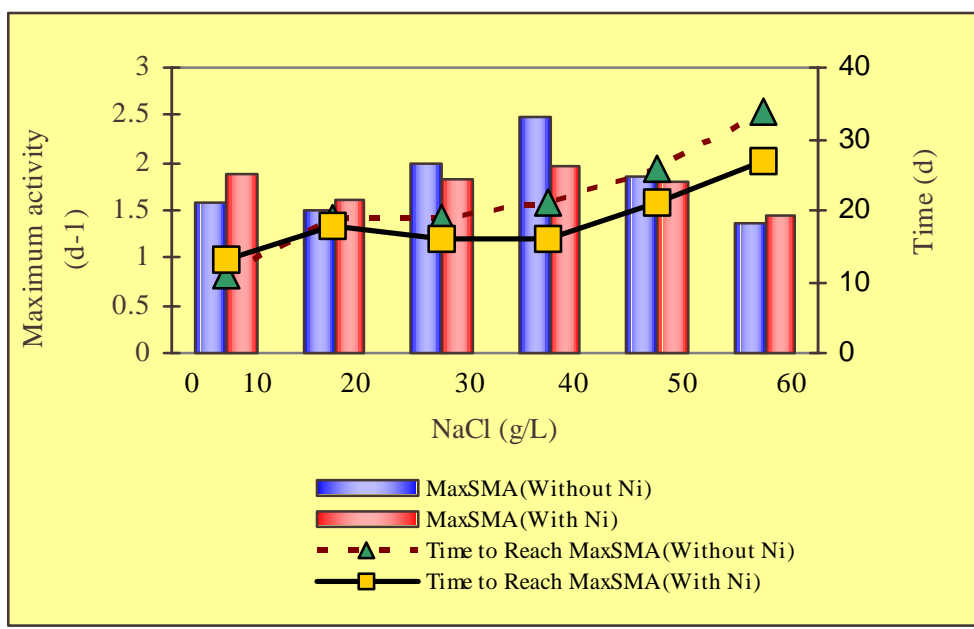

Fig. 11: Maximum SMA of digester sludge with and without nickel addition

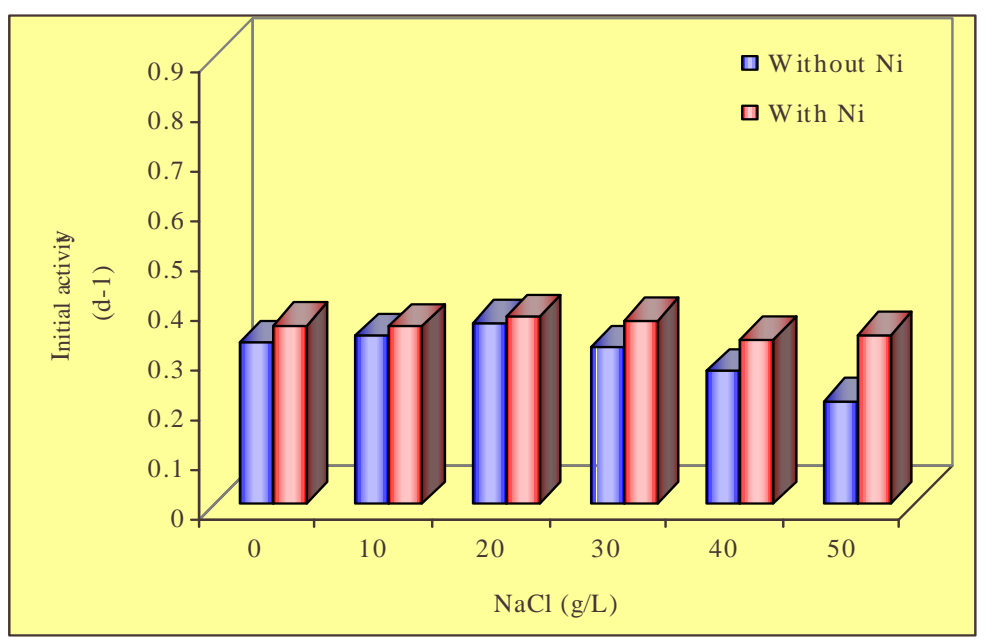

Fig. 12: Initial SMA of mixed culture with and without nickel addition 
3. For digester sludge in the long term response, the culture had the ability to adapt to the high salt concentration. With supplemental iron, the bacteria were able to increase their maximum SMA in the salt concentration of $0-10 \mathrm{~g} / \mathrm{L}$, and then the maximum SMA decreased. The maximum SMA values were less than the SMA with iron addition. Addition of nickel produced similar results as iron. In the long term effect, cobalt seemed to provide better result between the sodium concentrations of $0-30 \mathrm{~g} / \mathrm{L}$. It was able to increase maximum SMA of digester sludge in that range.

4. In short term response for the mixed culture, both iron and nickel increased the bacterial activity at all sodium concentrations. Although nickel had less potential to stimulate bacteria than iron, it never dropped into the inhibition range even at high sodium concentrations. The initial SMA was in the range of $0.3-0.4 \mathrm{~g}$ Acetate/ gVSSd. The effect of cobalt was different from other trace metals in this experiment. It could not stimulate bacteria in the sodium free medium. After increasing sodium, cobalt was able to help bacteria increase their initial activity. The optimum activity also occurred at sodium concentration of $20 \mathrm{~g} / \mathrm{L}$.

5. In the long term response, without supplemental trace metals, the maximum SMA of mixed culture increased from $1.5 \mathrm{~g}$ acetate/gVSSd to the maximum of $2.0 \mathrm{~g}$ Acetate/gVSSd at sodium chloride of $20 \mathrm{~g} / \mathrm{L}$, and then the SMA decreased to the inhibition range at salt concentrations of more than $35 \mathrm{~g} / \mathrm{L}$. Iron was able to stimulate the culture so that the maximum SMA with supplemental iron was in the stimulating range of sodium chloride. Nickel was also able to stimulate the mixed culture at all sodium chloride concentrations. The highest maximum SMA with nickel addition was $2.22 \mathrm{~g}$ Acetate/gVSSd at a sodium content of $30 \mathrm{~g} / \mathrm{L}$. At the salt concentration of $0-20 \mathrm{~g} / \mathrm{L}$, the maximum SMA with cobalt addition was less than the SMA without supplemental cobalt. However, with sodium concentration higher than $20 \mathrm{~g} / \mathrm{L}$, cobalt was able to stimulate the culture. The maximum SMA was also higher than that without supplemental cobalt.

\section{ACKNOWLEDGEMENT}

This research was conducted in the Environmental Engineering Laboratory with support from the Civil and Environmental Engineering Department of the George Washington University in Washington, DC, USA.

\section{REFERENCES}

Baxter, R. M. and Gibbons, N. E., (1956). Effect of Sodium and Potassium Chloride on Certain Enzymes of Micrococcus Halodenitrificans and Pseudomonas Salinaria. Can. J. Microbiol., 2 (6), 599-606.

Hovious, J. C., (1973). Identification and Control of Petrochemical Pollutants Inhibitory to Anaerobic Processes. Environmental Protection Technology Series; EPA-R2-73194, USEPA, Cincinnati, Ohio.

Hulshoff-Pol, L. W., Van de Worp, J. J. M., Lettinga, G. and Beverloo, W. A. (1986). Physical Characterization of Anaerobic Granular Sludge. In: Anaerobic Treatment. A Grown-up Technology. Aquatech; Amsterdam, 89-101.

Krongthamchat, K., and Riffat, R., (2001). Organic, Biodegradation in Saline Wastewater Using HalophileSupplemented Methanogenic Cultures. Proc. $9^{\text {th }}$ World Congress Anaerobic Digestion: Anaerobic Conversion for Sustainability, Part 2, Antwerpen, Belgium.

Macleod, R. A. and Onofrey, E., (1957). Nutrition and Metabolism of Marine Bacteria VI. Quantitative Requirements for Halides, Magnesium, Calcium, and Iron. Can. J. Microbiol., 3 (5), 753-759.

Mah, R. A., Smith, M. R. and Baresi, L., (1978). Studies on an Acetate-Fermenting Strain of Methanosarcina. Appl. Environ. Microbiol., 35 (6), 1174-1184.

Metcalf and Eddy, (2003)., Wastewater Engineering: Treatment, Disposal and Reuse. $4^{\text {th. }}$ Ed. McGraw Hill Inc., New York, USA.

Riffat, R. and Krongthamchat, K., (2006). Specific Methanogenic Activity (SMA) of Halophilic and Mixed Cultures in Saline Wastewater. Int. J. Environ. Sci. Tech., 2 (4), 291-299.

Speece, R. E., (1996). Anaerobic Biotechnology for Industrial Wastewaters. Archae Press., Nashville, TN, USA.

Speece, R. E., Parkin, G. F. and Gallagher, D., (1983). Nickel Stimulation of Anaerobic Digestion. Water Res., 17 (16), 677-683.

Takashima, M. and Speece, R. E., (1989). Mineral Requirements for High Rate Methane Fermentation of Acetate at Low SRT. J. Water. Pollut. Control. Fed., 61 (11-12), 16451650 . 


\section{AUTHOR(S) BIOSKETCHES}

Krongthamchat, K., Ph.D., is a Public Health Faculty in the Environmental Health Science Department at Khon Kaen University, Khon Kaen, Thailand. Email: kkanni@kku.ac.th

Riffat, R., Ph.D., is an associate professor in the Civil and Environmental Engineering Department of George Washington University, Washington, DC, USA. Email: riffat@gwu.edu

Dararat, S., Ph.D., is an environmental engineer at the Environmental, Ecological and Energy Department at Thailand Institute of Scientific and Technological Research, Bangkok, Thailand. Email:somchi2002@yahoo.com

\section{This article should be referenced as follows:}

Krongthamchat, K., Riffat, R. and Dararat, S., (2006). Effect of trace metals on halophilic and mixed cultures in anaerobic treatment. Int. J. Environ. Sci. Tech., 3 (2), 103-112. 